\title{
Current knowledge on the effects of humidity on physiological and psychological responses
}

\author{
Naoshi KaKITSUBA \\ Meijo University 1-501 Shiogamaguchi, Tempaku-ku, Nagoya-shi 468-8502, Japan \\ E-mail: naoshi@meijo-u.ac.jp TEL: 81-52-838-2382
}

(received on February 23, 2018, accepted on February 25, 2018)

\begin{abstract}
This paper introduces current knowledge on the effects of humidity on physiological and psychological responses. Reviewing this topic is quite challenging, for two reasons. The first is the fact that humidity is not an independent variable, but a dependent one. Since humidity is strongly associated with temperature, the effect of humidity per se may not be clearly defined. The second reason is that the physiological and psychological impacts of humidity have brought attention to various research fields related to human comfort and health, and knowledge has thus been accumulated from various disciplines. To arrange vast amounts of information, therefore, limitations on the scope are required before introduction. This paper investigated four different research fields: thermal physiology; exercise physiology; hygiene; and dermatology. Selected papers were then introduced chronologically to confirm current knowledge in each research field.

From the perspective of exercise physiology, the magnitude of heat stress during exercise in hot and humid environments appears to be clearly estimable from the current knowledge. From the perspective of hygiene, inspired gas conditioned to core temperature and fully saturated with water would provide the optimal condition for mucosal health and function. In terms of dermatology, properties of the stratum corneum appear to have been fully clarified, and water diffusion through the skin can be properly estimated from current knowledge. With thermal physiology and engineering related to indoor environments, current knowledge may be sufficient to provide optimal thermal environments in consideration of effect of humidity. However, discrepancies between physiological and psychological responses and large individual differences in psychological responses to variations in relative humidity have not yet been resolved, due probably to unknown mechanisms in the perception of humidity without specific receptors within the skin. Such issues may require further studies in all research fields related to human comfort and health.
\end{abstract}

Keywords: physiological and psychological response to humidity, thermal physiology, exercise physiology, hygiene, dermatology

\section{Introduction}

This review article introduces the effects of humidity on physiological and psychological responses. Some selections and limitations are required before introduction to make the scope of this review clear as possible. First, "relative humidity" was selected amongst many variables, such as absolute pressure, saturation vapor pressure, and dew point temperature, although each variable was developed for a specific purpose. Various research fields have paid attention to the physiological and psychological impacts of humidity, mainly with regard to improving human comfort and health. Knowledge has thus been accumulated from various disciplines. Second, the scope must necessarily be limited. For the purposes of this review paper, the four research fields of thermal physiology, exercise physiology, hygiene and dermatology were chosen, because each research field covers a different humidity range, as indicated in Figure 1. Considering this scope, selected papers were introduced chronologically to confirm current knowledge in each research field. Future topics are also discussed. 


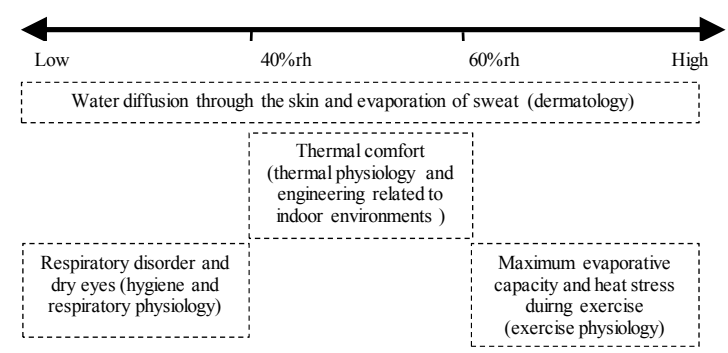

Figure 1. Ranges of relative humidity associated with research fields

\section{Studies on thermal physiology and engineering related to indoor environments}

2.1 Physiological and psychological responses to various thermal conditions

Yaglou (1927), Miura (1931), Winslow et al. (1937) and Gagge (1937) pioneered the study of physiological and psychological responses to various thermal conditions. After a lull in such research for more than a decade due to the World War II, a number of studies have recently been published. Studies into the effects of humidity on physiological responses have been published by, for example, Inouye et al. (1953), Hale (1958), Brebner et al. (1958), Hall (1962), Berglund and Gonzalez (1977), Shapiro et al. (1980), Candas et al. (1982), Candas et al. (1983), Candas and Hoeft (1995), and Toftum et al. (1998). Studies on the effects of humidity on psychological responses have been published by, for example, Koch (1963), McIntyre and Griffiths (1975), deDear et al. (1991), Ishi et al. (1993), Berglund (1998), Fountain et al. (1999), Beckera et al. (2003), Becker et al. (2003), Sunwoo et al. (2006b), Tsutsumi et al. (2007), Wan et al. (2009), Jing et al. (2012), Indragantia et al. (2014), He et al. (2016), Jin et al. (2017), and Rupp and Ghisi (2017). Rupp et al. (2015) then reviewed human thermal comfort in built environments, classified 466 articles, examined standards for indoor environments, and organized all the information on the influence on thermal comfort of personal variables such as age, weight, sex, and thermal history as well as environmental variables such as controls, layout, and air movement including humidity.

Regarding the studies on effects of humidity on psychological responses under various combinations of humidity and temperature, effects appear to be predictable, with general recognition of a substantial effect of high humidities, with little effect of low humidities under thermally neutral or warm environments. However, as Berglund (1998) commented that the effect of humidity on thermal balance has a clear mechanism but other effects on human sensation and health including on microorganisms have less clear mechanisms, a large individual difference in psychological responses was reported by, for example, Tsutsumi et al.
(2007) and Kakitsuba (2016). A large individual difference may result from unknown mechanisms of perception of humidity without a specific receptor in the skin, although textbooks on physiology (for example, Mashima, 1956) suggest the involvement of somatic sensation in humidity perception.

Kakitsuba (2016) then attempted to prove hypotheses about physiological responses to changes in relative humidity $(\mathrm{Rh})$ under thermally neutral, warm and hot conditions. Under thermally neutral and warm conditions, the first hypothetical response to an increase in relative humidity was a decrease in mean skin temperature (MST) due to increased mean evaporation rate $\left(E_{\mathrm{sk}}\right)$, and a second hypothetical response to a decrease in relative humidity was a decrease, increase, or no change in MST, depending on changes in $\mathrm{E}_{\text {sk. }}$. Under hot conditions, the third hypothetical response to an increase in relative humidity was an increase or decrease in MST upon decrease in relative humidity due to changes in $E_{s k}$, and the fourth hypothetical response to an increase in relative humidity was an increase in MST due to increased peripheral blood flow rate $\left(\mathrm{S}_{\mathrm{k}} \mathrm{BF}\right)$. Results from human experiments partly supported the first hypothesis, with the findings that MST was lower than control values at $28^{\circ} \mathrm{C}-80 \% \mathrm{Rh}$ and $\mathrm{E}_{\text {sk }}$ was higher than control values at $80 \%$ Rh at any tested temperature. The second hypothesis was also partly supported by findings that MST was lower than the control values at $28^{\circ} \mathrm{C}-40 \% \mathrm{Rh}$, with small changes in both MST and $\mathrm{E}_{\mathrm{sk}}$ at $30^{\circ} \mathrm{C}-40 \% \mathrm{Rh}$. The third and fourth hypotheses were supported by findings that MST was significantly higher at $36^{\circ} \mathrm{C}-70 \% \mathrm{Rh}(\mathrm{p}<0.01)$ than at $36^{\circ} \mathrm{C}-40 \% \mathrm{Rh}, \mathrm{E}_{\text {sk }}$ was significantly higher $(\mathrm{p}<0.01)$ at $70 \% \mathrm{Rh}$ than at $40 \% \mathrm{Rh}$, and SkBF correlated positively with MST. The mechanism of humidity perception is thus being clarified, although further studies are expected.

\subsection{Comfortable combinations of humidity and temperature}

Comfortable combination of humidity and temperature may have first been discussed by Robinson et al. (1945). Based on studies into the effects of humidity on physiological and psychological parameters published in the 1940s to 1960s, Woodcock and Breckenridge (1965) proposed a theoretical model based on the physical laws of heat and moisture exchange, and proved that a model with a variable convective heat transfer coefficient may correspond with experimental data under conditions of a consistently maintained mean skin temperature. Meanwhile, according to experimental results from 360 male and 360 female subjects who wore standard clothing under various combinations of ambient temperature and relative humidity, Nevins et al. (1966) proposed the temperature-humidity chart for thermal comfort indicated 


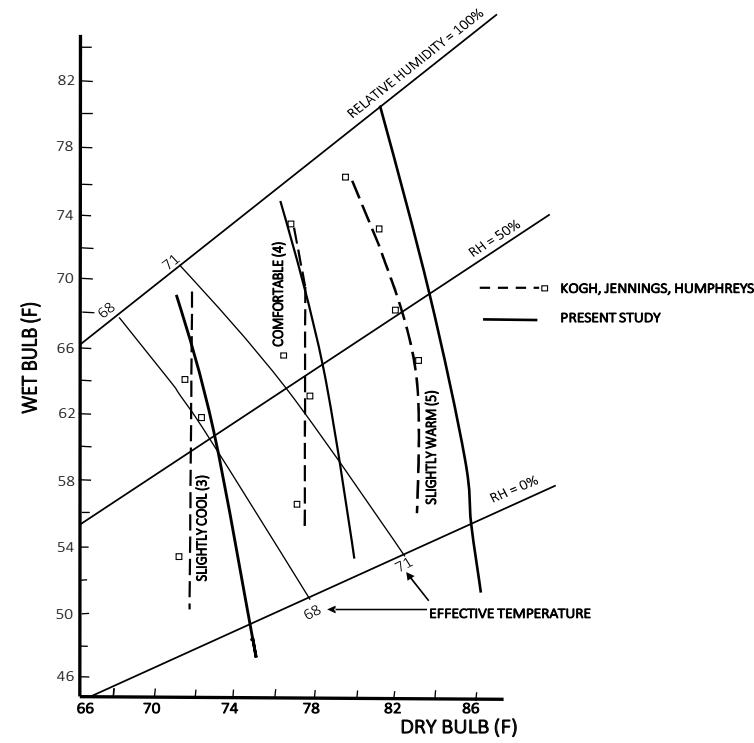

Figure 2. Thermal comfort lines as a combination of humidity and temperature, as proposed by Nevins et al. (1966)*

* The figure redrawn by the author.

\section{in Figure 2.}

Following those studies, Klemm and Hall (1972) tested the wet bulb-dry bulb index, effective temperature, wet bulb-globe temperature for predicting physiological strain in clothed, sitting male subjects, and showed equal mean skin temperature lines, equal rectal temperature lines, equal sweat production lines, and equal evaporative rate lines for useful prediction of the magnitude of heat strain. Wenzel (1978) analyzed data from human experiments in which unclothed young men were exposed at rest and at different treadmill work levels to various combinations of ambient temperature and air humidity. The slopes of the respective equivalence curves were plotted in psychrometric charts, and were found to correspond well with the Index of Physiological Effect proposed by Robinson et al. (1945). Mochida (1979) tested theoretical models to predict thermal comfort lines on the psychrometric chart. Analysis proved that the model with variable skin wettedness may correspond with experimental data under conditions of consistently maintained mean skin temperature, as indicated in Figure 3. Comfortable combinations of humidity and temperature thus demonstrated significant effects of high humidities, with little effects of low humidities under thermally neutral or warm environments.

Taking advantage of work published in the 1940s to 1980 s, recent studies, such as by Wan et al. (2009), Kampmann et al. (2011), Shi et al. (2013), and Indragantia et al. (2014), have focused on effective and energy-saving ways of air-conditioning indoor thermal environments to minimize thermal discomfort.

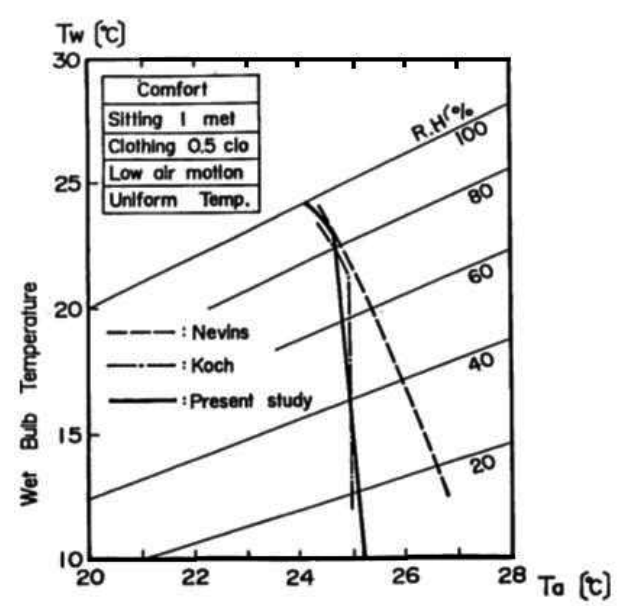

Figure 3. A thermal comfort line as proposed by Mochida (1979).

\subsection{Skin wettedness vs relative skin humidity}

Development of thermal indices and body temperature regulation models, which are outside the scope of this review paper, has required quantitative descriptions of the effect of humidity on physiological responses. The effect of humidity on physiological responses can be transformed into skin wettedness or relative skin humidity. Skin wettedness $(w)$ as proposed by Gagge (1937) is defined as:

$$
w=\mathrm{E}_{\mathrm{sk}} /\left[\mathrm{h}_{\mathrm{e}} \times\left(\mathrm{P}_{\text {sk }}{ }^{*}-\mathrm{P}_{\mathrm{a}}\right)\right] \quad \text { (ND) eq. } 1
$$

where, $E_{\text {sk }}$ is the amount of evaporative heat loss from the skin, $h_{e}$ is the evaporative heat transfer coefficient $\left(\mathrm{W} / \mathrm{m}^{2} \cdot\right.$ torr $), \mathrm{P}_{\mathrm{sk}}{ }^{*}$ is the saturated vapor pressure of the skin (torr), and $\mathrm{Pa}$ is ambient vapor pressure (torr).

Gagge et al. (1972) demonstrated the relationship between relative magnitude of warm discomfort and skin wettedness, as indicated in Figure 4. Thus, $w$ may not be associated with physiological responses, but rather with psychological responses. Since skin wettedness was incorporated into a 2-node model proposed by Gagge (1973) that has been widely used for

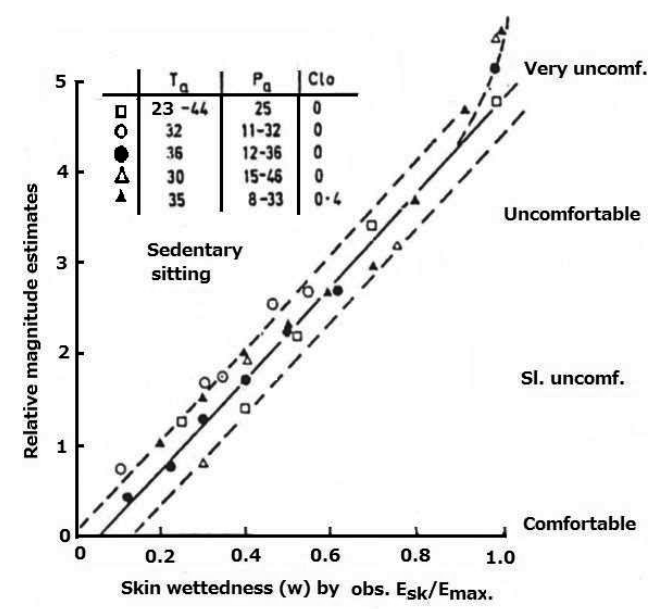

Figure 4. Relationship of relative magnitude of warm discomfort to skin wettedness (Gagge et al., 1972) 
predicting change in body temperature under various thermal conditions, a number of papers, such as by Horikoshi et al. (1986) (who demonstrated changes in the $w$ value under various combinations of relative humidity and temperature as indicated in Figure 5), Atmaca et al. (2006), Fukazawa and Havenith (2009) and Kampmann et al. (2011) have been published to demonstrate its usefulness. The effects of humidity on the $w$ value have thus been quantitatively verified.

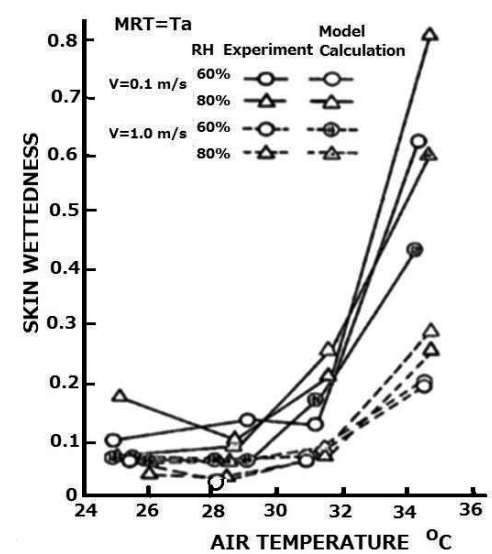

Figure 5. Change in skin wettedness at $60 \% \mathrm{Rh}$ and $80 \% \mathrm{Rh}$ at various air temperatures (Horikoshi et al., 1986)

On the other hand, relative skin humidity $\left(\mathrm{Rh}_{\mathrm{s}}\right)$ as proposed by Buettner (1934) is defined as:

$$
\mathrm{Rh}_{\mathrm{s}}=\left(\mathrm{E}_{\mathrm{sk}} / \mathrm{h}_{\mathrm{e}}+\mathrm{P}_{\mathrm{a}}\right) / \mathrm{P}_{\mathrm{sk}}{ }^{*} \quad \text { (ND) eq. } 2
$$

Although $\mathrm{Rh}_{\mathrm{s}}$ was first proposed by Buettner (1934), Mole (1948) contributed greatly to demonstration of its usefulness by explicating the behavior of $\mathrm{Rh}_{\mathrm{s}}$ for various combinations of humidity and temperature. Taylor and Buettner (1953) then evaluated the influence of evaporative forces upon the skin temperature dependency of human perspiration using $w$ and $\mathrm{Rh}_{\mathrm{s}}$. Comparing these two indices with data from human experiments, they concluded that $\mathrm{Rh}_{\mathrm{s}}$ was in reality far from the neat concept of skin wettedness. Furthermore, Goodman and Wolf (1969) measured insensible water loss from small areas of human skin using infrared gas analysis. The results indicated a nonlinear relationship between the amount of insensible water loss and ambient vapor pressure. Theoretical considerations were then proposed on the mechanism of water loss from human skin. Using the $\mathrm{Rh}_{\mathrm{s}}$ concept, they proved that water loss though evaporation takes place mainly through molecular diffusion combined with eccrine sweat gland secretion, which is dependent on the diameter of sweat glands. Toftum et al. (1998) recently tested the hypothesis that discomfort may be associated with skin humidity as well as $w$. Data from a human experiment in which 40 individuals were exposed to five levels of skin humidity confirmed that the model can be used to specify upper limits for indoor air humidity required to avoid discomfort due to skin humidity. Thus, the utility of two indices has been discussed.

\section{Studies on exercise physiology}

Exercise physiologists have focused on the limits of endurance during continuous exercise in hot and humid environments. Many studies have dealt with the effects of humidity on exercise performance. Maximum evaporation capacity $\left(\mathrm{Esk}_{\max }\right)$ is reduced when relative humidity becomes higher, because Esk $\mathrm{max}_{\text {ax }}$ is defined as the product of $h_{\mathrm{e}}$ and $\left(\mathrm{P}_{\mathrm{sk}}{ }^{*}-\mathrm{P}_{\mathrm{a}}\right)$. The amount of heat dissipation from the skin decreases due to a decrease in the product of $\mathrm{P}_{\mathrm{sk}}{ }^{*}-\mathrm{P}_{\mathrm{a}}$. If exercise continues in hot and humid environments, the rate of body heat storage increases. As a result, body temperature increases to the critical value of $40{ }^{\circ} \mathrm{C}$. When exercise continues, serious health disorders such as heat stroke may be expected. An antagonistic factor against increases in relative humidity is wind velocity. If wind velocity increases due to body movement or forced air movement, the $h_{e}$ value increases dramatically. The abbreviation effect by increasing air movement has thus become essential. This abbreviation effect can be expected under thermal conditions in which the ambient temperature is lower than the skin temperature. If the ambient temperature increases to above the skin temperature, sweat evaporation becomes the only pathway to heat loss. In this situation, humidity becomes the determining factor, because Esk $\mathrm{max}_{\max }$ is dependent on $\mathrm{P}_{\mathrm{a}}$.

Understanding the aforementioned criteria on body heat balance, the magnitude of heat stress in hot (warm) and humid environments has been studied, for example, by Niwa and Nakayama (1978), Smolander and Holmér (1991), Kondo et al. (1996), Keatisuwan et al. (1996), Maughan et al. (2012), and Shen and Zhu (2015). In exercise physiology considering thermal environments, the primary purpose is supposed to be evaluation of changes in exercise capacity or performance in hot and humid environments, where Esk $\mathrm{max}_{\max }$ becomes minimal because heat loss from the human body is limited. Under these specific situations, the magnitude of heat stress can be clearly estimated if individual and seasonal differences in sweating capacity (Keatisuwan et al., 1996) and heat acclimatization (Shen and Zhu, 2015) can be disregarded. In other words, accumulated knowledge on individual and seasonal differences in sweating capacity and heat acclimatization may depend on future studies to predict the magnitude of heat stress for various populations.

Few studies have looked at the combined effect of temperature during exercise. Watanabe et al. (1976, 1977) demonstrated an effect of humidity on physiological and psychological responses under a mild ambient temperature. Four clothed male subjects 
underwent experiments in which the ambient temperature was controlled to $23^{\circ} \mathrm{C}, 25^{\circ} \mathrm{C}, 27^{\circ} \mathrm{C}$ with relative humidities of $55 \% \mathrm{Rh}, 85 \% \mathrm{Rh}$, and $95 \% \mathrm{Rh}$, respectively, and then engaged in 20 -min exercise. The results indicated that relative humidity has little effect on physiological responses such as skin and body temperatures, but significant effects on psychological responses such as thermal sensation and discomfort under high relative humidity. Watanabe et al. then carried out experiments in 1977 with the same protocol, but the ambient temperature was controlled to $27^{\circ} \mathrm{C}$ and $29^{\circ} \mathrm{C}$ with relative humidities of $29 \% \mathrm{Rh}$ and $55 \% \mathrm{Rh}$. The results indicated that relative humidity has significant effects on physiological responses, since skin and body temperatures increased at $29^{\circ} \mathrm{C} / 55 \% \mathrm{Rh}$, and has significant effects on psychological responses as well. Discrepancies between physiological and psychological responses to varying relative humidity are to be shared with all scientists who work in related research fields.

Recently, Zhao et al. (2013) and Maughan and Otani (2012) studied the combined effects of temperature during exercise. Zhao et al. tried to evaluate effects of heat and different humidity levels on aerobic and anaerobic exercise performance in athletes. Nine male athletes performed $\mathrm{VO}_{2 \max }$ and Wingate anaerobic tests at $33^{\circ} \mathrm{C} / 20 \% \mathrm{Rh}$ and $33^{\circ} \mathrm{C} / 80 \% \mathrm{Rh}$. They found no difference in $\mathrm{VO}_{2 \max }$ between conditions, and concluded that different humidity levels had no effect on $\mathrm{VO}_{2 \max }$. Maughan and Otani (2012) tried to evaluate the influence of relative humidity on prolonged exercise capacity in a warm environment. Eight male volunteers performed four cycle exercise trials at $70 \%$ maximum oxygen uptake until volitional exhaustion in an environmental chamber maintained at $30.2 \pm 0.2^{\circ} \mathrm{C}$ with $\mathrm{Rh}$ of $24 \% \mathrm{Rh}, 40 \% \mathrm{Rh}, 60 \% \mathrm{Rh}$ and $80 \% \mathrm{Rh}$. The results showed no differences in core temperature or heart rate between trials, and suggested that exercise capacity at moderate intensity in a warm environment is progressively impaired as relative humidity increases. Effects of humidity on exercise capacity may thus depend on the intensity of exercise.

\section{Studies on hygiene}

Since hygiene is one of the interdisciplinary studies including medicine, many topics related to hygiene have been investigated. In the present review article, three different topics are introduced. The first is the effect of humidity on passengers in aircraft cabins as part of occupational health, because passengers who travel on airplanes experience very low relative humidity during flight. The second topic is dry eyes due to low humidity as part of medicine, and the last topic is the effect of humidity on ciliary movement as part of respiratory physiology.
Effects of humidity on passengers in aircraft cabins were investigated, for example, by Maehara et al. (1991), Alahmer et al. (2011), and Giaconia et al. (2013). Maehara et al. (1991) evaluated the physiological and psychological effects of the low-humidity, low-air pressure environment in passenger aircraft. Volume of basal tears, body weight change, arterial oxygen saturation and subjective evaluation of dryness, thermal and comfort sensations during a flight from Haneda to Naha were recorded. Air temperature was in the range of $25-27^{\circ} \mathrm{C}$ with $10 \% \mathrm{Rh}$ during flight. The results indicated that $40 \%$ of subjects reported "getting thirsty", "dryness of the eyes and nose", and "cool", since the evaporation rate increased with the lowest relative humidity. Alahmer et al. (2011) also studied the effects of relative humidity and temperature control in the cabin. According to the thermodynamic and psychometric analyses, changing relative humidity along with dry bulb temperature in cabins can improve the human comfort sensations by reducing the heat removed. Giaconia et al. (2013) reported results from experimental investigations of short-haul domestic flights that showed the indoor air quality aboard commercial aircrafts for 14 domestic flights less than 90 min long, and confirmed the possibility of improving hygrometric conditions in aircraft cabins without needing humidification systems.

Dry eyes due to low humidity may be one of the main interests amongst ophthalmologists. For example, Mathers et al. (1993), Abelson et al. (2002), and McCulley et al. (2006) investigated the effect of low humidity on dry eyes. McCulley et al. (2006) investigated the relationship between relative humidity and aqueous tear evaporation to elucidate the possible significance of this relationship in normal individuals and patients with aqueous tear deficiency. Ocular surface evaporation was determined using evaporometry and calculated for two ranges of $25-35 \% \mathrm{Rh}$ and $35-45 \%$ $\mathrm{Rh}$ in the clinical patient population. The results showed that increased evaporation at lower humidity has significant clinical implications for patients with aqueous-deficient dry eyes. Exposure to $25-35 \% \mathrm{Rh}$ is thus confirmed to induce dry eyes.

The effect of the quality of inspired air on human respiratory functions has been one of the main interests amongst respiratory physiologists, to provide optimal inspired air to patients forced to breath via a cannula with an atomizer. Although many studies have been published by respiratory physiologists, for example, McFadden et al. (1985), Baile et al. (1987), Lee et al. (1996), Sato et al. (2003), Takahashi et al. (2008), and Takada (2015), two review papers are introduced here. Williams et al. (1996) reviewed 200 articles on respiratory tract physiology and humidification. A relationship between inspired gas humidity and temperature, 
exposure time to a given humidity level and mucosal function were then discussed. As a result, they suggested that the optimal temperature and humidity are core temperature and $100 \% \mathrm{Rh}$, but no studies have yet looked at this relationship beyond $24 \mathrm{~h}$. Another review article published by Rankin (1998) tried to answer the question "what is optimum humidity?" and suggested mucociliary transport velocity and airway workload as reliable markers, as indicated in Figure 6, because both suggest that inspired gas conditioned to core temperature and fully saturated with water would provide the best conditions for mucosal health and function over prolonged periods. Thus, knowledge of the optimal humidity for inspired gas may be available for future study. However, optimal humidity has not been clearly defined. A few intangible factors such as individual differences in the function of ciliary movement may need to be considered.

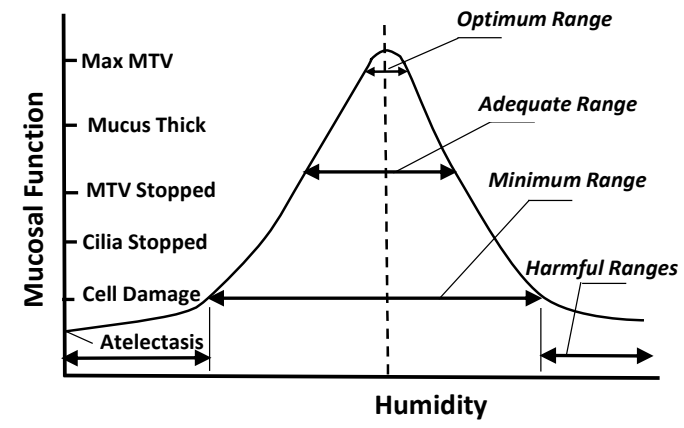

Figure 6. How mucosal function might vary with deviations in inspired humidity from core temperature and 100\% relative humidity (Rankin, N. 1998).

\section{Studies on dermatology}

The main interest of dermatologists is to define the mechanisms of water diffusion through the skin. Humidity is recognized as one of the influential factors involved in water diffusion through the skin. One of the common queries is regarding the discrepancy between water diffusion from the skin and theoretical estimations based on physics. Assuming that the tissue layer is fully saturated with water, the amount of water through the skin must follow the laws of physics, which is the process of water diffusion through the skin layer. However, the reality is not like the theory. The amount of water diffused through the skin changes in a different manner, particularly when sweating occurs due to increasing temperature. In the $1940 \mathrm{~s}$ and $1950 \mathrm{~s}$, to answer this question, many dermatologists (King, 1945; Blank, 1952, 1953; Buettner, 1953; Peiss et al., 1956) extensively studied changes in water diffusion through the skin and the role of the stratum corneum. The stratum corneum can absorb water very readily and would thus become permeable to water diffusion. On the other hand, the stratum corneum becomes less permeable when water is lost. The manner of transdermal water loss may thus depend on dynamic changes in the permeability of the stratum corneum. Based on studies in the 1950s and 1960s, Scheuplein and Blank (1971) published a review article on the permeability of the skin.

These studies appear fundamental to describing physiological responses to varying relative humidities, with the exception of hot and humid conditions where excessive sweating occurs. The conclusion from those studies is almost complete, as indicated in Figure 7, which Blank included in his paper (1953). In the 1960s, dermatologists continuously focused on water diffusion through the skin. For example, Onken and Moyer (1963) quantitatively reconfirmed the role of the stratum corneum. They reported that the rate of water vapor transpiration through normal excised skin with the stratum corneum at $10-20^{\circ} \mathrm{C}$ is $2.9 \mathrm{gm} / \mathrm{cm}^{2} / \mathrm{h}$, increasing to $229 \mathrm{gm} / \mathrm{cm}^{2} / \mathrm{h}$ when the skin becomes barrier-deficient.

Thus, the mechanism of water diffusion through the skin has been obviously described, but seasonal and sex differences in water diffusion through the skin for given thermal conditions were not extensively discussed until the 1980s. Yoshikuni et al. (1983, 1984 and 1985) investigated the role of the superficial horny layer, and in particular reported on the hydration state of the superficial horny layer in summer and winter in 1983, and evaluated factors influencing the water content of this layer. The results showed that the water content of the horny layer of the skin was high in summer and low in winter, and the water content in this layer may be dependent on vapor pressure and the amount of sweating.

Other than water diffusion through the skin to the environment, dermatologists have paid attention to socalled "negative insensible perspiration". For example, Buettner (1953) conducted experiments in which a local area of skin was exposed to different vapor pressures in air and water solutions. The results showed that vapor passes through non-sweating skin in

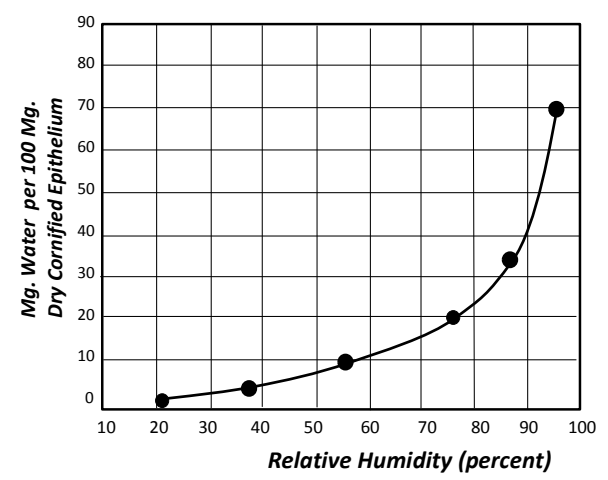

Figure 7. Relationship between water content of cornified epithelium and relative humidity of the environment at $23^{\circ} \mathrm{C}$ (Blank, 1953)**

*This figure was redrawn by the author. 


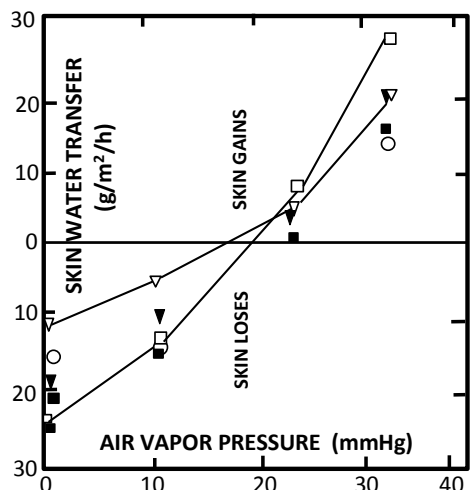

Figure 8. Water gain or loss of small area of skin on the forearm exposed to air at four different humidities with no sweating (Buettner, 1953)*

*This figure was redrawn by the author.

proportion to the air vapor pressure. As indicated in Figure 8 , if vapor pressure exceeds $21 \mathrm{mmHg}$, the skin gains water as "negative insensible perspiration".

Since then, this "negative insensible perspiration" has been continuously studied. For example, Johnsen et al. (2011) recently attempted to clarify the sorption properties of human stratum corneum. The results indicated that water entered the human stratum corneum much more rapidly compared to its exit at relative humidities lower than 50\% Rh. Graice and Bettley (1967) and Bettley and Grice (1967) reported that vasoconstriction and vasodilation had no significant effects on transepidermal water loss, and change in body temperature was unrelated to transepidermal water loss, whereas decreasing skin temperature was accompanied by decreasing transepidermal water loss. Following those studies, Katherine et al. (1972) reported the effect of ambient humidity on transepidermal water loss, and demonstrated that the diffusion coefficient of the stratum corneum alters with changing ambient humidity, based on the finding that transepidermal water loss at $2-3 \% \mathrm{Rh}$ was the same as that at $70 \% \mathrm{Rh}$.

Sweat gland activity was also extensively studied by dermatologists in the 1940s and 1950s, for example, by Pinson (1942), Randall and Hertzman (1953), Peiss et al. (1956), and Randall and Peiss (1957). They focused on the relationship between hydration of the skin and its effect on sweating and evaporative water loss. However, once sweating is induced by increasing air temperature, humidity does not play an important role in evaporative water loss from the skin. In this review article, therefore, details of those studies on sweat gland activity are not included. However, the role of blood flow should not be disregarded. According to Pinson (1942), the rate of blood flow through the skin appears to have an effect on cutaneous insensible perspiration rate with the exception that it changes skin temperature.

\section{Conclusion}

In exercise physiology, where the main interest is the effect of exposure of the exercising human body to hot and humid environments, the magnitude of heat stress during hot and humid environments appears to be clearly estimable from current knowledge. In hygiene, including respiratory physiology, the main interest is to provide controlled inspired air to patients, provision of inspired air controlled to core temperature and saturated with water vapor is known to be optimal, although the definition of optimal humidity does require further study. In dermatology, where the main interest is the mechanism of water diffusion through skin, since the properties of human stratum corneum appear to be fully clarified, the amount of water diffusion through the skin can be properly estimated from current knowledge. However, sex and seasonal differences in the amount of water diffusion through the skin may remain for future clarification. In thermal physiology and engineering relate to indoor environments, current knowledge appears to comply with the requirement for providing thermal environments within a comfortable range in consideration of the effects of humidity. However, psychological responses to varying humidities may not yet be precisely understood, due probably to unknown mechanisms of perception of humidity without specific receptors in the skin. This may require further investigation.

\section{Acknowledgement}

This study was partly supported by the research center for future standards of living environments, Meijo University. This manuscript has been edited by native English-speaking experts from FORTE Science Communications.

\section{References}

Abelson, M. B., Ousler, G. W. 3rd, Nally, L. A., Emory, T. B. (2002) Dry eye syndromes: diagnosis, clinical trials, and pharmaceutical treatment-"improving clinical trials”, Adv. Exp. Med. Biol., 506: 1079 $-1086$.

Alahmer, A., Omar, M. A., Mayyasb, A., Dongri, S. (2011) Effect of relative humidity and temperature control on in-cabin thermal comfort state: Thermodynamic and psychometric analyses, Applied Thermal Engineering, 31: 2636-2644.

Atmaca, I., Yigit, A. (2006) Predicting the effect of relative humidity on skin temperature and skin wettedness, Journal of Thermal Biology 31 (2006) 442-452.

Baile, E. M., Dahlby, R.W., Wiggs, B.R., Parsons, G.H., Pare, P. D. (1987) Effect of cold and warm dry air hyperventilation on canine airway blood flow, J. Appl. Physiol. 62, 526-532. 
Becker, S., Potchter, O., Yaakov, Y. (2003) Calculated and observed human thermal sensation in an extremely hot and dry climate. Energy and Buildings, 35: 747-56.

Berglund, L. G., Gonzalez, R. R. (1977) Evaporation of sweat from sedentary man in humid environments, J. Appl. Physiol., 42(5): 767-72.

Berglund, L. G. (1998) Comfort and humidity, ASHRAE Journal, 40(8), 35-41.

Bettley, F.R., Grice, K.A. (1967) The influence of ambient humidity on transepidermal water loss, The British J. Dermatology, 78, 48-79.

Blank, I. H. (1952), Factors which influence the water content of the stratum corneum. J. Invest Dermat., 18 , pp.433-440

Blank, I. H. (1953) Further observation on factors which influence the water content of the stratum corneum, J. Invest Dermat., 21, pp.259-271.

Brebner, D. F., McK Kerslake, D., Waddell, J. L. (1955) The diffusion of water vapour through human skin, J. Physiol., 132, 224-231.

Brebner, D. F., Kerslake, D. M., Waddell, J. L. (1958) The effect of atmospheric humidity on the skin temperatures and sweat rates of resting men at two ambient temperatures, J. Physiol., 144, 299-306.

Buettner, K. (1934) Die Warmeubertragung durch Leitung und Konvection, Verdunslung and Strahlung in Bioklimatologic und Meteorologie, Berlin, Springer.

Buettner, K. (1953) Diffusion of water and water vapor through human skin, J. Appl. Physiol., 6(4): 229-241

Candas, V., Libert, Y., Sagot, J. P., Vogt, J. J. (1982) Thermophysiological responses to humid heat: sex differences, J. Physiol. (Paris), 78(2): 240-2.

Candas, V., Libert, Y., Vogt, J. J. (1983) Sweating and sweat decline of resting men in hot humid environments, Eur. J. Appl. Physiol., 50, 223-234

Candas, V., Hoeft, A. (1995) Clothing, assessment and effects on thermophysiological responses of man working in humid heat, Ergonomics, 38(1): 115-27.

deDear, R. J., Leow, K.G., Ameen, A. (1991) Thermal comfort in the humid tropics. Part II. Climate chamber experiments on thermal acceptability in Singapore ASHRAE Transactions Issue, 1, 880-886.

Fountain, M., Arens, E., Xu, Bauman, T. F., Oguru, M. (1999) An investigation of thermal comfort at high humidities, ASHRAE Transactions 105 (2): 94-103.

Fukazawa, T., Havenith, G. (2009) Differences in comfort perception in relation to local and whole body skin wettedness, Eur J Appl Physiol, 106: 15-24 DOI 10.1007/s00421-009-0983-z

Gagge, A. P. (1937) A new physiological variable associated with sensible and insensible perspiration, American J. Physiol., 120, 277-287.

Gagge, A. P., Stolwijk, J. A. J., Nishi, Y. (1972) An effective temperature scale based on a simple model of human physiological regulatory response, ASHRAE Trans., 77: 247-262.

Gagge, A. P. (1973) Rational temperature indices of man's thermal environment and their use with 2-node model of his temperature regulation, Federation Proceedings, 32, 1572-1582.

Giaconia, C., Orioli, A., Gangi, A. D. (2013) Air quality and relative humidity in commercial aircrafts:

An experimental investigation on short-haul domestic flights, Building and Environment 67, 69-81.

Goodman, A. B., Wolf, A. V. (1969) Insensible water loss from human skin as a function of ambient vapor concentration, J. Appl. Physiol., 26(2): 203-207.

Graice, K., Bettley, F.R. (1967) The effect of skin temperature and vascular change on the rate of transepidermal water loss, Brit. J. Dermatology, 79: 582-588.

Hall, J. F. Jr. (1962) Effect of vapor pressure on physiological strain and body heat storage, J. Appl. Physiol., 18(4): 808-811.

He, Y., Li, N., Zhang, W., Peng, J. (2016) Overall and local thermal sensation \& comfort in air-conditioned dormitory with hot-humid climate, Building and Environment, 101(15), 102-109.

Hale, F. C., Westland, K. A., Taylor, C.L. (1958) Barometric and vapor influences on insensible weight loss, J. Applied Physiol., 12(1), 20-28.

Horikoshi, T., Kobayashi, Y., Tsuchikawa, T., Fukushima, S. (1986) Verification of corrected humid operative temperature, thermal velocity field and reduced-effective humid field as thermal environmental indices, J. Architectural, planning and environmental engineering, 380, 12-23. (Written in Japanese)

Indragantia, M., Ooka, R., Rijal, H. B., Bragera, G. S. (2014) Adaptive model of thermal comfort for offices in hot and humid climates of India, Building and Environment, 74, 39-53.

Inouye, T., Hick, F. C., Telse, S. E., Keeton, R. W. (1953) Effect of relative humidity on heat loss of men exposed to environments of 80,76 and $72 \mathrm{~F}$, ASHVE Transactions, 59, 329.

Ishi, A., Iwamoto, S., Amashita, M., Atayama, T., Sshiotsuki, Y. (1993) An experimental study on the effect of humidity on thermal sensations of people in summer, Therm. Biol., 18 (5/6), 387-391.

Jing, S., Li, B., Tan, M., Liu, H. (2012) Impact of relative humidity on thermal comfort in a warm environment, Indoor Built Environ., 22(4), 598-607.

Jin, L., Zhang, Y., Zhang, Z. (2017) Human responses to high humidity in elevated temperatures for people in hot-humid climates, Building and Environment, 114, 257-266.

Johnsen, G. K., Norlen, L., Martinsen, Ø. G., Grimnes, 
S. (2011) Sorption properties of the human stratum corneum, Skin Pharmacol. Physiol. 2011; 24(4):1908, 2011.

Kakitsuba, N. (2016) Physiological responses to changes in relative humidity under thermally neutral, warm and hot conditions, Journal of Thermal Biology, 59, 86-91.

Katherine, G., Sattar, H., Baker, H. (1972) The effect of ambient humidity on transepidermal water loss, The J. of Investigative Dermatology, 58(6): 343-346.

Kampmann, B., Bröde, P., Fiala, D. (2011) Physiological responses to temperature and humidity compared to the assessment by UTCI, WGBT and PHS, Int. J. Biometeorol., 56(3): 505-13.

Kondo, N., Nishiyasu, T., Ikegami, H. (1996) The influence of exercise intensity on sweating efficiency of the whole body in a mild thermal condition, Ergonomics, 39(2): 225-31.

Keatisuwan, W., Ohnaka, T., Tochihara, Y. (1996) Physiological responses of women during exercise under dry-heat condition in winter and summer, Appl Human Sci., 15(4): 169-76.

King, G. (1945) Permeability of keratin membranes to water vapour, Trans. Faraday Soc., 41, 479-487

Klemm, F. K., Hall, J. F. Jr. (1972) Utility of heat stress indices and effect of humidity and temperature on single physiologic strains, J. Applied, Physiol., 33(4), 436-440.

Koch, W. (1963) Humidity sensations in the thermal comfort range, Architectural Science Review, 6(1), 33-34.

Lee, M. C., Kim, H. H., Chediak, A. D., Wanner, A. (1996), Airway blood flow responses to temperature and humidity of inhaled air, Respir. Physiol., 105(3): 235-9, 1996.

Maehara, N., Watanabe, A., Kurosawa, S. (1991) The physiological and psychological effects of low humidity and low air pressure environment in passenger aircrafts J. Science of Labour, 67(6), 275-292.

Marino, F. E., Mbambo, Z., Kortekaas, E., Wilson, G., Lambert, M. I., Noakes, T. D., Dennis, S. C. (2000) Advantages of smaller body mass during distance running in warm, humid environments., Pflügers Arch., 441(2-3): 359-67.

Mashima, H. (1956) Physiology, Bunko-do, Tokyo, Japan, 216. (Written in Japanese)

Mathers, W. D., Binarao, G., Petroll, M. (1993) Ocular water evaporation and the dry eye. A new measuring device. Cornea, 12: 335-340.

Maughan, R. J., Otani, H. (2012) Influence of relative humidity on prolonged exercise capacity in a warm environment, Eur. J. Appl. Physiol., 112: 2313-2321, doi 10.1007/s00421-011-2206-7.

McCulley, J. P., Aronowicz, J. D., Uchiyama, E., Shine,
W. E., Butovich, I. A. (2006) Correlations in a change in aqueous tear evaporation with a change in relative humidity and the impact, Am. J. Ophthalmol., 141: 758-760.

McFadden, E. R. Jr., Pichurko, B. M., Bowman, H. F., Ingenito, E., Burns, S., Dowling, N., Solway, J. (1985) Thermal mapping of the airways in humans, J Appl Physiol., 58(2): 564-70.

McIntyre, D. A., Griffiths, I. D. (1975) Subjective responses to atmospheric humidity, Environmental Research, 9 (1), 66-75.

Miura, U. (1931) The effect of variations in relative humidity upon skin temperatures and sense of comfort, American J. Hygiene, 13, 432.

Mochida, T. (1979) Wet heat loss from skin surface, Jpn. J. Biometeorology, 16(1): 30-35. (Written in Japanese)

Mole, R. H. (1948) The relative humidity of the skin, J. Physiol. 107, 399-411.

Nevins, R. G., Rohles, F. H., Springer, W., Feyerherm, A. M. (1966) A temperature-humidity chart for thermal comfort of seated persons, ASHRAE Transactions, 72(1), 283-291.

Niwa, K., Nakayama, T. (1978) Thermoregulation during exercise in high humidity environments (in Japanese with English abstract) Jpn. J Phys Fit Sport 27: 11-18.

Onken, H. D., Moyer, C. A. (1963) The water barrier in Human epidermis, Arch. Derm., 87, 90-96.

Peiss, C. N., Randall, W.C., Hertzman, A. B. (1956) Hydration of the skin and its effect on sweating and evaporative water loss, J. Invest. Dermatol. 26: 459-470.

Pinson, E. A. (1942) Evaporation from human skin with sweat glands inactivated, Am. J. Physiol., 137, 492-503.

Randall, W. C., Hertzman, A.B. (1953) Dermatomal recruitment of sweating, J. Appl. Physiol., 5(8), 399-409.

Randall, W. C., Peiss, C. N. (1957) The relationship between skin hydration and the suppression of sweating, J. Invest. Dermatol. 28, 435-441.

Rankin, N. (1998) What is optimum humidity?, Respirat. Care Clinics of North America, 4: 2, 321-328.

Robinson, S., Turrell, E. S., Gerking, S. D. (1945) Physiologically equivalent conditions of air temperature and humidity. Am. J. Physiol., 143: 21-32.

Rupp, R. F., Vásquez, N. G., Lamberts, R. (2015) A review of human thermal comfort in the built environment, Energy and Buildings, 105(15), 178-205.

Rupp, R. F., Ghisi, E. (2017) Predicting thermal comfort in office buildings in a Brazilian temperate and humid climate, Energy and Buildings, 144, 152-166. 
Sato, M., Fukayo, S., Yano, E. (2003) Adverse environmental health effects of ultra-low relative humidity indoor air, J. Occup. Health, 45: 133-136.

Scheuplein, R. J., Blank, I. H. (1971) Permeability of the skin, Physiological Reviews, 51(4): 702-747.

Shapiro, Y., Pandolf, K. B., Avelline, B. A., Pimental, N., Goldman, R. F. (1980) Physiological responses of men and women to humid and dry heat, Physiol.: Respirat. Environ. Exercise Physiol. 49 (1): 1-8.

Shen, D., Zhu, N. (2015) Influence of the temperature and relative humidity on human heat acclimatization during training in extremely hot environments, Building and Environment, 94, 1-11.

Shi, X., Zhu, N., Zheng, G. (2013) The combined effect of temperature, relative humidity and work intensity on human strain in hot and humid environments, Building and Environment, 69, 72-80.

Smolander, J., Holmér, I. (1991) Individual response to physical work in the heat in relation to sweating and skin blood flow, Int. Arch. Occup. Environ. Health, 63(3): 225-6.

Sunwoo, Y., Chou, C., Takeshita, J., Murakami, M., Tochihara, Y. (2006) Physiological and subjective responses to low relative humidity in young and elderly men, J. Physiol. Anthropol., 25(3): 229-38.

Takada, S. (2015) Evaluation of sensation of dryness in airway under low humidity environment by heat and moisture transfer model of respiration, Energy Procedia 78, 2772-2777.

Takahashi, F., Takahashi, M., Toya, S., Morita, O. (2008) Study on the relationship between subjective oral dryness and simulated saliva oral mucosal moisture, Prosthodont Res Pract 7: 78-81

Taylor, C. L., Buettner, K. (1953) Influence of evaporative forces upon skin temperature dependency of human perspiration, J. Appl. Physiology, 6, 113-123.

Toftum, J., Jorgensen, A. S., Fanger, P. O. (1998) Upper limits for indoor air humidity to avoid uncomfortably humid skin, Energy and Buildings 28, 1-13

Tsutsumi, H., Tanabe, S., Harigaya, J., Iguchi, Y., Nakamura, G. (2007) Effect of humidity on human comfort and productivity after step changes from warm and humid environment, Building and Environment, 42: 4034-42.

Wan, J. W., Yang, K., Zhang, W. J., Zhang, J. L. (2009) A new method of determination of indoor temperature and relative humidity with consideration of human thermal comfort, Building and Environment, 44, 411-417.
Watanabe, A., Kimotsuki, K., Inoue, S., Kimura, K., Yonemoto, J., Miura, T., Matsuura, F., Asao, T. (1976) Effect of the humidity on the physiological and psychological responses under the mild ambient temperature (Rep.1) J. Science of Labour, 52(11), 635-650.

Watanabe, A., Kimotsuki, K., Inoue, S., Kimura, K., Yonemoto, J., Miura, T., Matsuura, F., Asao, T. (1977) Effect of the humidity on the physiological and psychological responses under the mild ambient temperature (Rep.2) J. Science of Labour, 53(3), 199-218.

Wenzel, H. G. (1978) Heat stress upon undressed man due to different combinations of elevated environmental temperature, air humidity, and metabolic heat production: a critical comparison of heat stress indices, J. Hum. Ergol. (Tokyo). 7(2): 185-206.

Williams, R., Rankin, N., Smith, T., Galler, D., Seakins, P. (1996) Relationship between the humidity and temperature of inspired gas and the function of the airway mucosa. Crit. Care Med 24: 1920-1929.

Winslow, C.-E. A., Herrington, L.P., Gagge, A. P. (1937) Physiological reaction of the human body to varying environmental temperature. American J. Physiol., 120, 1-20.

Woodcock, A. H., Breckenridge, J. R. (1965) A model description of thermal exchange for the nude man in hot environments, Ergonomics, 223-235.

Yaglou, C. P. (1927) Temperature, humidity and air movement in industries: The effective temperature index. J. Ind. Hyg., 9: 297-309.

Yoshikuni, K., Tagami, H., Shirahama, S. (1983) Measurement of the hydration state of the superficial horny layer in summer and winter: Evaluation of the several factors influencing the water content of the horny layer, the Japanese J. Dermatology, 93(5), 491-495.

Yoshikuni, K. (1984) Assessment of the function of skin surface lipids influencing the water content of the stratum corneum, Nippon Hifuka Gakkai Zasshi 94: 1253-1258. [In Japanese]

Yoshikuni, K., Tagami, H., Inoue, K., Yamada, M. (1985) Evaluation of the influence of ambient temperature and humidity on the hydration level of the stratum corneum, Nippon Hifuka Gakkai Zasshi 95: 591-595. [In Japanese]

Zhao, J., Lorenzo, S., Nan, A., Wenping, F., Lai, L., Cui, S. (2013) Effects of heat and different humidity levels on aerobic and anaerobic exercise performance in athletes, Journal of Exercise Science \& Fitness, 11, 35-41. 